\title{
A case report on usage of rituximab on complicated steroid-dependent nephrotic syndrome
}

\author{
Shravan Jayachandran, S. Suwitha, A. Priya, K. Arun Chander*
}

Department of Clinical Pharmacology, Apollo Children's Hospital, Chennai, Tamil Nadu, India

Received: 22 October 2020

Revised: 05 December 2020

Accepted: 07 December 2020

\section{*Correspondence:}

Dr. K. Arun Chander,

Email: clinicalpharmaach_cni@apollohospitals.com

Copyright: (c) the author(s), publisher and licensee Medip Academy. This is an open-access article distributed under the terms of the Creative Commons Attribution Non-Commercial License, which permits unrestricted non-commercial use, distribution, and reproduction in any medium, provided the original work is properly cited.

\begin{abstract}
Nephrotic syndrome (NS) is one of the common yet challenging childhood disease. Treating NS with immunosuppressants like corticosteroids is typically effective. However, there are significant evidences which displayed resistance patterns to the former drugs. Here in this case, a male patient came to the nephrology department with the history of steroid dependant nephrotic syndrome with complaint of its infrequent relapse. The condition was complicated since, the patient was on multiple steroids even after which there were recurrent episodes of syndrome. Considering the status, Mycophenolate mofetil was added as a supportive treatment for the management of the disease along with steroids, still the outcome was unremarkable. Hence, rituximab was ordered (four cycles). The outcome this time was appreciable, rituximab administration produced a positive result. No events were recorded during the treatment duration.
\end{abstract}

Keywords: Nephrotic syndrome, Immunosuppressants, Relapse, Resistant patterns

\section{INTRODUCTION}

Idiopathic nephrotic syndrome (INS) is considered to be one of the most common chronic glomerular diseases in children. A total of $80-90 \%$ of patients with childhood idiopathic nephrotic syndrome achieves remission with steroid therapy (steroid-sensitive nephritic syndrome (SSNS)). However, approximately $50 \%$ of children with SSNS develop frequently relapsing nephritic syndrome (FRNS) or steroid-dependent nephrotic syndrome (SDNS). About $20 \%$ of children who are receiving immunosuppressive agents still show frequent relapses or steroid dependence during or after treatment, which can be defined as complicated FRNS or SDNS. ${ }^{1}$

Treatment of steroid-dependent nephrotic syndrome, particularly in patients who have failed to respond to multiple immunosuppressive drugs, remains challenging. ${ }^{2}$
Corticosteroids have been the main treatment for decades and are effective in most children with INS but, about $15 \%$ of these children become resistant to steroid. There might have an increased risk of developing steroid toxicity in sensitive children who are receiving steroids yet frequently relapse occurs where alternative immunosuppressive medicines such as cyclophosphamide, mycophenolate mofetil (MMF) and calcineurin inhibitors (CNIs) can be used to induce and/or maintain remission of INS and hence helps in improving their clinical course.

Among the immunosuppressive agents Rituximab, a chimeric anti-CD20 monoclonal antibody that was originally developed to treat patients with B-cell nonHodgkin's lymphoma, but it also showed significant benefits in children and adults with a variety of renal disorders, including vasculitis, lupus nephritis, and NS is currently used for treating SSNS. ${ }^{3}$ Although the exact 
mechanism(s) underlying primary NS is not yet wellestablished, however earlier studies suggested that podocyte foot process effacement and heavy proteinuria occurs when $\mathrm{T}$ cells becomes the main effector cells. However, more recent evidence suggests that B cells may play a previously unrecognized yet significant role in the development of INS. ${ }^{4}$

\section{CASE REPORT}

A 5 years old male child came to department of nephrology with a known case of SDNS frequent relapse and last relapse was on November 2019. On the day of admission patient's vitals were recorded as- blood pressure (BP) 100/70 $\mathrm{mmHg}$ and pulse $116 \mathrm{bpm}$. Upon laboratory investigation it was found that patient's hemoglobin, packed cell volume, platelet count and erythrocyte sedimentation rate (ESR) were abnormal. Urine analysis showed abnormal counts in serum creatinine $(0.2 \mathrm{mg} / \mathrm{dL})$, serum albumin $(2.7 \mathrm{~g} / \mathrm{dL})$, total serum protein $(5.6 \mathrm{~g} / \mathrm{dL})$ and also protein and creatinine ratio spot urine (9.07) which signifies proteinuria. The child was currently on steroid regimen (tablet prednisolone) with calcium and vitamin D3 supplements.

The past history shows that the child was diagnosed on December 2018 as SDNS at the age of 2 (protein $\sim 4 \mathrm{~g} / \mathrm{dL}$ ) and was on steroid regimen which is tablet prednisolone $15 \mathrm{mg}$ once daily (in morning) till the urine albumin is negative and then the dose was reduced to $10 \mathrm{mg}$ OD for 2 weeks and then further reduced to $7.5 \mathrm{mg}$ OD for another 2 weeks followed by $5 \mathrm{mg}$ OD daily till the next review. But when the dose of steroid was tapered, patient's condition relapsed (protein $\sim 4 \mathrm{~g} / \mathrm{dL}$ and lower limb edema) and therefore it was necessary to start the use of tablet levamisole $50 \mathrm{mg}$ once daily every alternative days on April 2019 with the steroid regimen (Prednisolone $10 \mathrm{mg}$ OD for 2 weeks then $7.5 \mathrm{mg}$ OD till next review) with routine spot urine analysis.

As previously mentioned, as the dose was tapered, patient was seen with oedamatous condition in face and lower limb (protein $>4 \mathrm{~g} / \mathrm{dL}$ and edematous face). Thus, the patient was advised on July 2019 to start with Mycophenolate mofetil (MMF) therapy, where patient received MMF at a dose of $250 \mathrm{mg}$ twice daily orally with steroid regimen. Tablet prednisolone was initially given at a dose of $25 \mathrm{mg}$ OD in first week, $20 \mathrm{mg}$ OD dose at second week and $15 \mathrm{mg}$ OD dose till next review was planned alone with the routine spot urine tests. During the next visit the nephrologist reduced the dose of Prednisolone to $12.5 \mathrm{mg}$ OD for 2 weeks followed by 10 mg OD till next review along with Pantoprazole and calcium supplement. On October 2019, as urine protein was $<3.5 \mathrm{~g} / \mathrm{dL}$, Prednisolone dose was further reduced to $7.5 \mathrm{mg}$ OD for 2 weeks followed by $7.5 \mathrm{mg}$ OD for 2 weeks and $5 \mathrm{mg}$ OD till next visit along with tablet MMF $250 \mathrm{mg}$ BD, pantoprazole and calcium supplement.
On January 2019, the patient was seen with relapse of condition like edematous face and lower limbs and thus was admitted in Apollo Children's hospital. Since relapse was seen with MMF therapy, the nephrologist planned to start with injection rituximab at a dose of $350 \mathrm{mg} / \mathrm{m} 2$ weekly once with a total of 4 cycles. Medicines like injection Avil $1 \mathrm{~mL}$ intravenous (IV) STAT, injection hydrocortisone $50 \mathrm{mg}$ IV STAT, tablet paracetamol 350 $\mathrm{mg}$ per oral (PO) STAT/SOS, nebulizer budecort $0.5 \mathrm{mg}$ and nebulizer levolin $0.63 \mathrm{mg}$ given as STAT 1 hour prior to the rituximab therapy as a prophylaxis therapy. Injection Rituximab $300 \mathrm{mg}$ (Based on patient BSA) has been mixed with $300 \mathrm{~mL}$ of normal saline (NS) for dilution. The total of $300 \mathrm{mg}$ in $300 \mathrm{~mL}$ NS was administered as $10 \mathrm{~mL} /$ hour at $1 \mathrm{st}$ hour, $20 \mathrm{~mL} /$ hour at $2 \mathrm{nd}$ hour, $30 \mathrm{~mL} / \mathrm{hr}$ at $3 \mathrm{rd}$ hour, $40 \mathrm{~mL} /$ hour at 4 th hour, $50 \mathrm{~mL} /$ hour for next 4 hours to bring up $300 \mathrm{~mL}$ over 8 hours. No events were recorded during the treatment duration.

\section{DISCUSSION}

In patients with steroid-dependent nephrotic syndrome, treatment remains quiet challenging especially for those who experience failure responding to multiple immunosuppressive drugs. Also, NS is considered to be more seen in Asian children rather than in American and Caucasian children. ${ }^{3}$ As per Kidney Disease: Improving Global Outcomes (KDIGO) guidelines states that if a patient is having Urine protein $>3.5 \mathrm{~g} / \mathrm{d}$ and serum albumin $\leq 2.5 \mathrm{~g} / \mathrm{dl}$ with edema then the patient can be said to have NS. ${ }^{5}$ For the current case as the steroid dose was tapered, the urine protein was seen to be $>3.5 \mathrm{~g} / \mathrm{dL}$ in multiple occasions and hence concluded as Complicate SDNS and started steroid regimen protocol.

In earlier studies it was clearly mentioned that levamisole is well tolerated with minimal side effects in patients who are having NS. ${ }^{6}$ As the dose of steroids tapered, relapse seen and was forced to initiate tablet levamisole $50 \mathrm{mg}$ given OD.

Rituximab, an anti-CD20 monoclonal antibody, has been successfully used in the last decade to treat patients with refractory NS, including SDNS..$^{7-9}$ However, the place of RTX in the treatment of SDNS remains to be established because of the low quality of evidence according to the recently issued clinical practice guideline for kidney diseases by KDIGO5 where it suggested that RTX can be considered only in children with SDNS, who have continuing frequent relapses despite optimal combinations of prednisolone and corticosteroid-sparing agents, and/or who have serious adverse effects of therapy. ${ }^{10}$

Case series report that RTX has considerable efficacy against childhood SDNS, although many patients tend to relapse within 1 year consistently with the re-emergence of B cells if receiving RTX at a dose of $375 \mathrm{mg} / \mathrm{m}^{2}$ BSA once weekly for 4 weeks. ${ }^{11}$ 
It appears that RTX is a very effective drug for childhood SDNS or FRNS to maintain remission (average duration of remission is 12-20 weeks based on previous studies), which reduces the frequency of relapses and enables the reduction or discontinuation of corticosteroids and other immunosuppressive agents. It may also be more cost effective than taking a daily medication with all of its needed monitoring and may contribute for improving the growth of children. ${ }^{12-14}$ Four weekly doses of RTX may improve the chances of response by compensating for the amount of medication lost in the urine in some children with NS (90). However, several studies have demonstrated no significant difference in the response rate in children between 1 and 2 doses versus three to four doses. ${ }^{15}$

\section{CONCLUSION}

Idiopathic NS is one of the most frequent glomerular diseases in childhood. Although most cases respond to steroid treatment, approximately $40 \%$ of children with NS develop refractory NS. These patients are commonly treated with immunosuppressants, such as cyclosporine-A, cyclophosphamide, mizoribine (MZB) and MMF. However, the immunosuppressants used are having significant adverse effects in children and hence it is difficult to use for a prolonged duration in children. RTX is an effective and increasingly used as a treatment option to induce or prolong clinical remission of NS in children. Although the exact mechanism in unknown, RTX may very well-exert its beneficial effects through multiple mechanisms of action. There is now growing evidence for supporting its safety and efficacy in children with SDNS or FRNS in inducing prolonged remission, which enables in reduction of corticosteroid exposure and its side effects. Also, these immunosuppressive agents such as MMF and calcineurin inhibitors has been proven to be effective in children with SDNS, they need to be taken twice daily to maintain remission. Thus, using an IV medication such as RTX may prove additionally valuable in children where adherence to medications is in question.

\section{ACKNOWLEDGEMENTS}

We would like to express our sincere gratitude towards the Department of Nephrology (Pediatrics) for helping us by providing all the data necessary to incorporate in this case report.

Funding: No funding sources Conflict of interest: None declared

Ethical approval: Not required

\section{REFERENCES}

1. Iijima K, Sako M, Kamei K, Nozu K. Rituximab in steroid-sensitive nephrotic syndrome: lessons from clinical trials. Pediatr Nephrol. 2018;33:1449-455.

2. Koumi ME. Rituximab in steroid-dependent nephrotic syndrome. Iran J Kidney Dis. 2013;6(7):502-06.
3. Kallash M, Smoyer WE, Mahan JD. Rituximab Use in the Management of Childhood Nephrotic Syndrome. Front Pediat.r 2019;178(7):1-10.

4. Eddy AA, Symons JM. Nephrotic syndrome in childhood. Lancet. 2003;362:629-39.

5. Cattran DC, Feehally J, Cook HT, Liu ZH, Fervenza FC, Mezzano SA et al. Kidney Disease: Improving Global Outcomes (KDIGO) Glomerulonephritis Work Group: KDIGO Clinical practice guideline for glomerulonephritis. Kidney Int. 2012;2:139-274.

6. Kalra S, Kanitkar M, Tiewsoh K. Use of levamisole in children with nephrotic syndrome: A retrospective study to examine its adverse effects in children with nephrotic syndrome. J Mar Med Soc. 2017;19(2):8790

7. Benz K, Dötsch J, Rascher W, Stachel D. Change of the course of steroid-dependent nephrotic syndrome after rituximab therapy. Pediatr Nephrol. 2004;19:794-7.

8. Gilbert RD, Hulse E, Rigden S. Rituximab therapy for steroid-dependent minimal change nephrotic syndrome. Pediatr Nephrol. 2006;21:1698-1700.

9. François H, Daugas E, Bensman A, Ronco P. Unexpected efficacy of rituximab in multirelapsing minimal change nephrotic syndrome in the adult: first case report and pathophysiological considerations. Am J Kidney Dis. 2007;49:158-61.

10. Kimata T, Hasui M, Kino J, Kitao T, Yamanouchi S, Tsuji $S$ et al. Novel Use of Rituximab for SteroidDependent Nephrotic Syndrome in Children. Am J Nephrol. 2013;38:483-8.

11. Hofstra JM, Deegens JKJ, Wetzels JFM. Rituximab: effective treatment for severe steroid dependent minimal change nephrotic syndrome? Nephrol Dial Transplant. 2007;22:2100-2.

12. Iorember F, Aviles D, Kallash M, Bamgbola O. Cost analysis on the use of rituximab and calcineurin inhibitors in children and adolescents with steroiddependent nephrotic syndrome. Pediatric Nephrol. 2018;33:261-7.

13. Takura T, Takei T, Nitta K. Cost-effectiveness of administering rituximab for steroid-dependent nephrotic syndrome and frequently relapsing nephrotic syndrome: a preliminary study in japan. Sci Rep. 2017;7:46036.

14. Takura T, Takei T, Nitta K. Socioeconomics of Administering Rituximab for Nephrotic Syndrome. Contrib Nephrol. 2018;195:110-9.

15. Delbet JD, Leclerc G, Ulinski T. Idiopathic nephrotic syndrome and rituximab: may we predict circulating $\mathrm{B}$ lymphocytes recovery? Pediatr Nephrol. 2018;34:529-32.

Cite this article as: Jayachandran S, Suwitha S, Priya A, Chander KA. A case report on usage of rituximab on complicated steroid-dependent nephrotic syndrome. Int J Basic Clin Pharmacol $2021 ; 10: 130-2$. 